\title{
ANALYSIS OF THE CANADIAN BOREAL FOREST USING ENHANCED RESOLUTION ERS-1 SCATTEROMETER IMAGERY
}

\author{
Clarence J. Wilson III
}

\author{
and \\ David G. Long \\ Brigham Young University \\ 459 CB, Provo, UT 84602 \\ Voice: 801-378-4884, FAX: 801-378-6586 \\ e-mail: wilsonj@nscat.ee.byu.edu
}

Abstract -- Scatterometer backscatter measurements $\left(\sigma^{\circ}\right)$ are primarily and traditionally used to estimate wind speed and direction over the ocean. This paper presents an investigation of the backscatter coefficient of boreal forest and neighboring vegetation regions. ERS-1 backscatter $\mathcal{A}$-values of the Canadian boreal forest are imaged using a resolution enhancement algorithm for this analysis. Regions of boreal forest, tundra, and grassland are individually analyzed over the extent of the ERS-1 scatterometer's data set (1992-1995). The annual variation of the mean $\sigma^{\circ}$ value for each region is presented. Distinct seasonal variations exist for these vegetation types. Boreal forests exhibit a stronger response $(\sim 2.5$ $\mathrm{dB}$ ) during warm summer months than during the snow and ice covered winter months. The results of this study indicate good potential for further analysis of boreal forest regions using ERS-1 scatterometer data.

\section{INTRODUCTION}

The European Remote Sensing satellite, ERS-1, carries a scatterometer radar which measures the radar backscattering coefficient $\left(\sigma^{\circ}\right)$ over the entire earth. The primary purpose of this measurement is to determine wind speeds and directions over the ocean. Recently, consideration of scatterometer measurements over land surfaces has been investigated $[1,2,3]$. The ERS-1 scatterometer measurement data provides $50 \mathrm{~km}$ resolution of these surfaces and repeated coverage every 4-10 days. While this revisit time is very good, the spatial resolution is low and thus limits applications of such land studies.

Researchers in the Microwave Earth Remote Sensing (MERS) group at BYU have been actively developing a technique for enhancing the resolution of scatterometer data [4]. This resolution enhancement technique, called Scatterometer Image Reconstruction (SIR), appears to have the ability to increase resolution from the original
$>50 \mathrm{~km} /$ pixel to $\sim 25 \mathrm{~km} /$ pixel. SIR imagery, along with the frequent coverage of spaceborne scatterometers like ERS-1, can aid in the study of large land regions with ecological significance. Such research has already shown SIR's usefulness in the study of the Amazon rain forests [5] and Antarctic sea ice [6].

Boreal Forests: Description and Scientific Interest

Boreal forests are vast coniferous forests characterized by needleleaf deciduous and needleleaf evergreen trees (common varieties are spruce, pine, fir, aspen, birch, hemlock, and larch), and lichen woodlands. Typically, a few species will dominate the forest stand making the boreal forest a rather homogeneous ecosystem [7]. Boreal forests are found in cool, temperate zones of the northern hemisphere. They are typically found north of the $50^{\text {th }}$ North parallel and south of the Arctic Circle. Thus, Canada, Alaska, Siberia, and Scandinavia are the primary political entities containing boreal forests. Ecologically, they fit between arctic tundra and broadleaf deciduous hardwoods.

Because they cover such massive regions (approximately 15 million $\mathrm{km}^{2}$ worldwide), boreal forests are an important factor in understanding the global ecosystem. For most of this century, boreal forests have periodically been studied to access their condition and monitor changes that occur in their ecosystems. Research has sought to determine how timber resources are being managed (especially with regard to wood production), the effects of increasing pollution from modern society (i.e., acid rain and global warming theories).

Natural cycles of the forest and how the forest adapts to subsequent change is the subject of other research. Remote sensing techniques including aerial photography and SAR imagery have found use in studies requiring infrequent image collection (on the order of years) and 
studies of small ( $\left.<10 \mathrm{~km}^{2}\right)$ sections of forest. However, as Shubert et al. have suggested, "The processes that control [boreal forest] patterns can change in importance as the space- and time-scales of the pattern of interest are changed." Thus, the understanding of boreal forest cycles over small sections or short time periods does not necessarily apply to the cycles of the forest on macroscopic levels or over long time periods. This paper investigates the use of ERS- $1 \sigma^{\circ}$ measurement imagery enhanced by the SIR algorithm as a technique for studying boreal forests over long time periods and large forest regions.

\section{Scatterometer $\sigma^{\circ}$ Measurements and SIR Imagery}

The ERS-1 scatterometer's primary purpose is to measure vector wind velocities over the ocean. Of course, these measurements are not made directly. Rather, it measures the radar backscatter coefficient $\sigma^{\circ}$ of the ocean's surface. A model function is then used to estimate wind direction and speed. The normalized radar backscatter coefficient, or normalized radar cross-section, is defined by the radar equation to be

$$
\sigma^{\circ}=\frac{(4 \pi)^{3} R^{4} L}{G^{2} \lambda^{2} A} \frac{P_{S}}{P_{t}}
$$

where $R$ is the range to the surface, $L$ accounts for system losses, $\mathrm{G}$ is antenna gain, $\mathrm{A}$ is the reflecting surface area, $\lambda$ is the wavelength of the electromagetic energy, $P_{S}$ is the received backscatter power, and $P_{t}$ is the transmitted backscatter. Thus, a simple interpretation of $\sigma^{\circ}$ is the ratio of received power to transmitted power normalized for geometric and system considerations.

Kennett and $\mathrm{Li}$ demonstrated that $\sigma^{\circ}$ values over land are well modeled by the first-order linear function

$$
10 \log _{10} \sigma^{\circ}(\theta)=\mathcal{A}+\mathcal{B}\left(\theta-40^{\circ}\right)
$$

where $\theta$ is the incidence angle of the observation. Thus, $\mathcal{A}$ may be interpreted as a constant backscatter coefficient for the land type of the reflecting surface. $\mathcal{B}$ yields the interpretation as a measure of the backscatter coefficient's dependence on incidence angle for the land type of the reflecting surface. Prior research has demonstrated a strong correlation between $\mathcal{A}$ and $\mathcal{B}$ and vegetation type and surface topology $[3,5,6]$.

The major drawback of using spaceborne scatterometer $\sigma^{\circ}$ measurements to study vegetation and land surfaces is the rather coarse resolution of the scatterometer measurements (for the ERS-1 scatterometer $\sim 50 \mathrm{~km} /$ pixel). On the other hand, spaceborne scatterometers offer a distinct advantage over other common remote sensing methods (namely, aerial and SAR): frequent and consistent fly-overs. The ERS-1 scatterometer provides repeated coverage of the entire world every 4-10 days. Further, the quantity of data produced by scatterometer measurements is much more manageable than that of SAR measurements. These characteristics make spaceborne scatterometer $\sigma^{\circ}$ measurements an attractive resource for study of surface vegetation on a regional or global scale.

In an effort to improve the resolution of scatterometer measurements, an image reconstruction algorithm has been developed and refined by members of the BYU Microwave Earth Remote Sensing group [4]. The Scatterometer Image Reconstruction (SIR) algorithm takes advantage of spatial overlap in scatterometer measurements made at different times in order to enhance image resolution. It produces estimates of the $\mathcal{A}$ and $\mathcal{B}$ coefficients discussed above at a pixel spacing of $8.9 \mathrm{~km}$ for ERS-1 data. Thus, spaceborne scatterometer measurements in conjunction with SIR image resolution enhancement provide medium-scale resolution of vegetation regions around the world with a short interim fly-over time. This characteristic of SIR scatterometer imagery is exploited as a tool for studying boreal forests over vast land regions and long time periods.

\section{ANALYSIS OF BOREAL FOREST $\sigma^{\circ}$ PATTERNS}

The potential of SIR imagery for studying boreal forest regions is investigated by first making SIR imagery of the Canadian boreal forest region from original $\sigma^{\circ}$ measurements. Next, small subregions of the different vegetation types in the study area are examined over a four-year period to investigate interannual backscatter variations.

\section{SIR Imagery}

SIR imagery is created from the raw ERS- $1 \sigma^{\circ}$ data set of the region enclosed by latitudes $50^{\circ} \mathrm{N}$ and $70^{\circ} \mathrm{N}$ and longitudes $140^{\circ} \mathrm{W}$ and $55^{\circ} \mathrm{W}$ over the period Jan. 1 , 1992 through Oct. 31, 1995 (the extent of the data set at press). In order to assure quality SIR images, the data was grouped into 15 day periods and then processed using the SIR algorithm, producing an $8.9 \mathrm{~km}$ pixel-spaced image of each time period.

Fig. 1 shows two SIR images thus produced. Fig. 1(a) is the image for February 15-28, 1993. Snow and ice present during this winter period result in a nearly homogeneous backscatter $\mathcal{A}$-value over the entire image. However, prominent geographic features (such as the Pacific Ocean, Rocky Mountains, and Hudson Bay) are still apparent. There is not much distinction, however, over the majority of the land mass due to the snow and ice cover mentioned above. Differentiating boreal forests from other vegetation types does not appear to be straightforward during the winter months.

Fig. 1(b) shows the region for August 15-31, 1993. Here, a distinctive band running diagonally from the northwest to southeast corners through the center of 


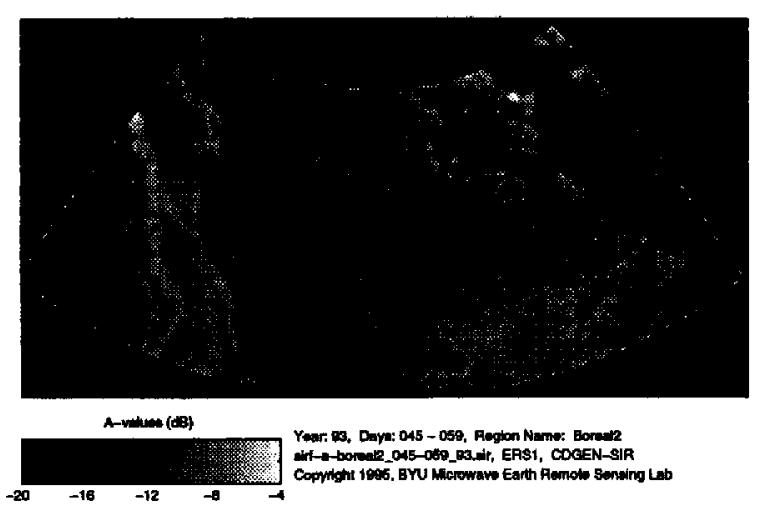

(a) Feb. 15-28, 1993

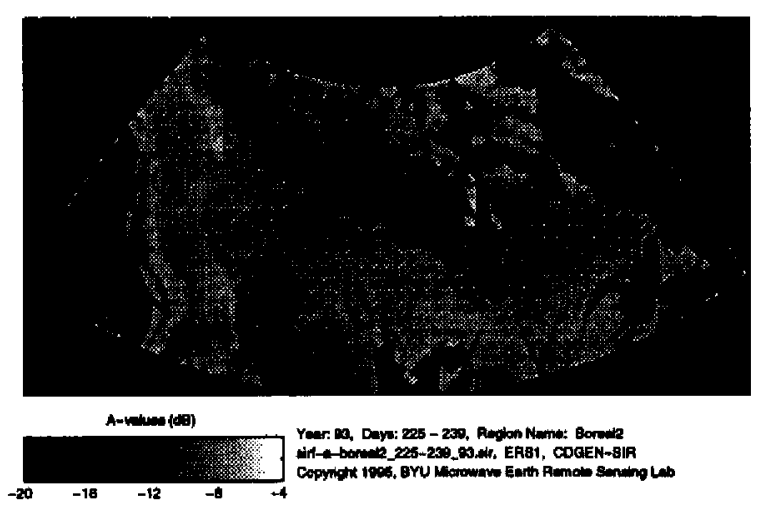

(b) Aug. 15-31, 1993

Figure 1: Enhanced Resolution Images of Canada. The overall darkness in the upper image is the result of snow and ice coverage. The bright band running across central Canada in the lower image is the Boreal forest region.

Canada is readily apparent. This feature is the boreal forest. The northern extent of the grasslands/farmlands of the Great Plains appears in this image south and west of the boreal forest. The tundra region appears north and east of the boreal forest. The many small black spots throughout the image are lakes which were covered with ice in the February image and now appear as other bodies of water. This image appears to be more useful for vegetation studies than the February image due to the overall higher contrast levels of the backscatter $\mathcal{A}$-values among different vegetation regions.

One noticeable problem with 1(b) is the missing image data at the bottom center and other places in the image. This is a result of missing scatterometer data over this region during this time period. The scatterometer was probably turned off and the satellite's SAR turned on over these regions. Missing data is a problem for many of the images produced in this series.

\section{Seasonal Variations}

The backscatter characteristics of smaller, localized, homogeneous vegetation subregions are next analyzed over several annual periods. Six such subregions are selected from the Canadian boreal forest and neighboring vegetation types. A map of Canada displaying the location of the six subregions is found in Figure 2. Two regions of needleleaf evergreen forest, one in the north and the other in the south (Sub $1 \& 2$ ) are chosen. Two regions of lichen woodland are selected, again one in the north and the other in the south (Sub 4 \& 3). Finally, a region of tundra (Sub 5) and a region of grassland at the northern extreme of the Great Plains (Sub 6) are chosen to demonstrate further backscatter characteristic differences.

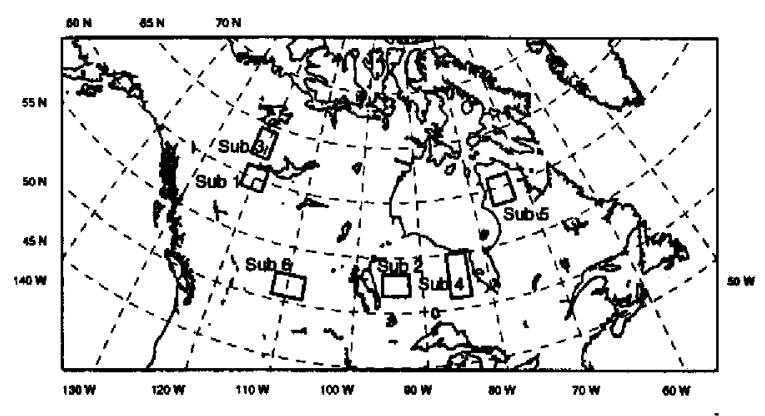

Figure 2: A map of Canada indicating the six subregions used for temporal analysis of Boreal forest backscatter. The vegetation types of the subregions are as follows: Sub $1 \& 2$, Boreal Forest; Sub 3 \& 4, Lichen Woodland; Sub S, Tundra; and, Sub 6, Grassland.

Fig. 3 is a graph of the mean $\mathcal{A}$-values estimated by the SIR algorithm for the needleleaf evergreen forest subregions (\#1 and \#2). In these plots, the dashed line represents the weighted average of the $\mathcal{A}$-values from all four years. Portions of the subregions missing data (as discussed above) are not included in calculating such statistics. The backscatter response is 2-3 dB stronger during the summer than the winter. Both plots display a distinctly increasing slope during early spring that climaxes around JD 120 (May 1). This is assumed to represent spring vegetation growth following the meltoff of winter snow and ice. A symmetric feature occurs in the late summer season as the autumn vegetation cycle and winter freezing begins. Note that this occurs earlier for the northern subregion (about JD 260, or midSeptember) than the southern subregion (about JD 280, or mid-October).

Fig. 4 is a similar plot for lichen woodland subregions (\#3 and \#4). Here, again, the spring and autumn vegetation cycles are apparent yielding a 2.5-3 dB difference between winter and summer. The lichen woodland spring and autumn transitions are more rapid than those of the boreal forest. Note that for both vegetation types 

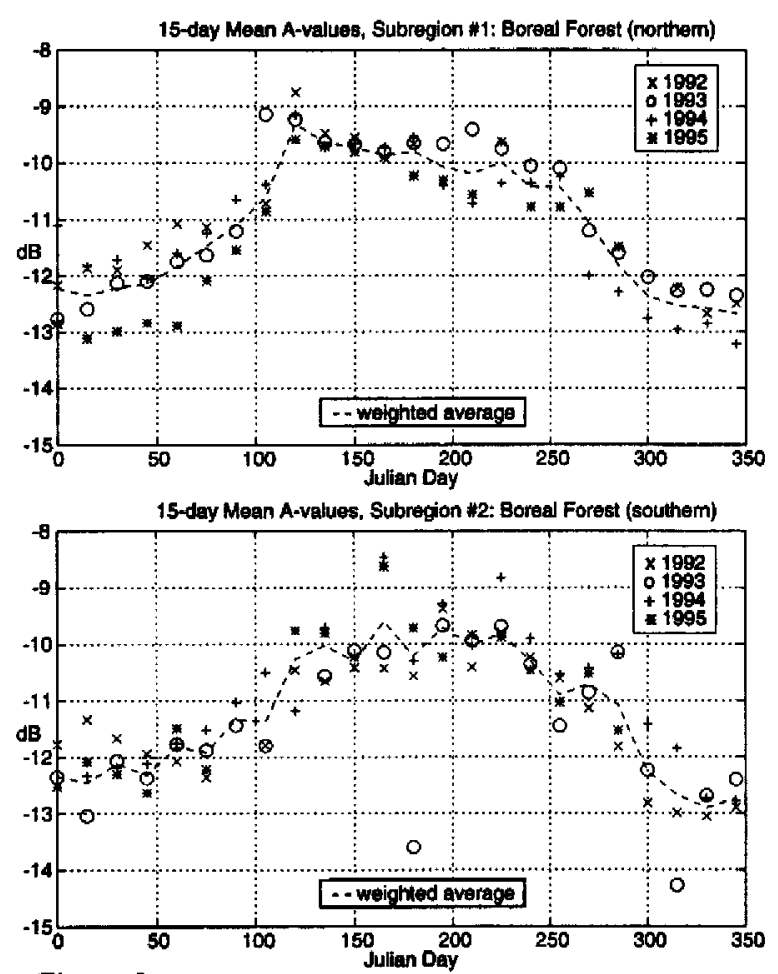

Figure 3: Mean A-values for subregions I and 2 (Boreal forest) for 1992-1995

the northern subregions (\#1 and \#3) have more abrupt transitions than their southern counterparts.

Figure 5 is the mean $\mathcal{A}$-value plot for the tundra subregion (subregion \#5) and a section of the grasslands at the northern extent of the Great Plains (subregion \#6). The tundra region exhibits several singular behaviors. Around JD 135 (mid-May), a significant decrease (1.5 $\mathrm{dB}$ ) in the mean $\mathcal{A}$-value is observed which returns to its prior value within 30 days. It is thought that this behavior corresponds to the spring melt. Later, around JD 255, a sharp decrease in mean $\mathcal{A}$-value again occurs and then returns to its nominal value about $\mathrm{JD} 0$ (three months later). No explanation appears readily appropriate for this phenomena. In the lower plot, an interesting behavior for the grassland subregion appears. Two interesting features appear around JD 105 and JD 270. These days correspond to mid-April and late September. The plot around these days has sharp dips in the mean $\mathcal{A}$-values. It seems reasonable to suggest these correspond to the planting and harvesting seasons for the farmers in this region. This demonstrates the sensitivity of backscatter coefficient measurements to changes in soil moisture content when the land is plowed and turned over.

In Fig. 6 the weighted mean $\mathcal{A}$-values for all six subregions are plotted for comparison. From this figure it is clear that the grassland subregion (\#5) backscatter is significantly less than the boreal forests, lichen woodlands, and tundra year-round. The tundra region (\#6)
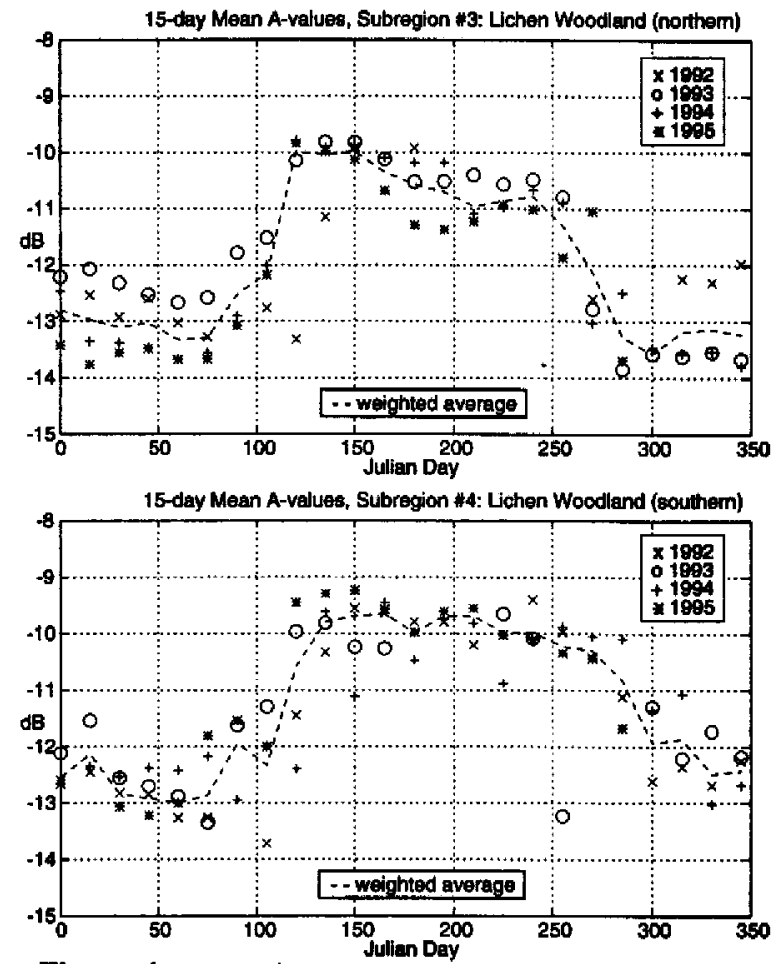

Figure 4: Mean A-values for subregions 3 and 4 (Lichen Woodland) for 1992-1995

backscatter coefficient is less than the boreal forest and lichen woodlands during summer by about $1.5 \mathrm{~dB}$, but during the winter season is approximately the same or slightly greater. It appears the boreal forest and lichen woodland regions all reach a peak in spring around JD 120. However, date of the autumn fall-off varies from region to region. Thus, the seasonal patterns of boreal forests and the surrounding vegetation regions are very pronounced.

\section{CONCLUSION}

Study of the boreal forest regions using enhanced resolution imagery produced by the SIR algorithm demonstrates that a dramatic seasonal transition exists for the boreal forest's backscatter coefficient $\left(\sigma^{\circ}\right)$. This interannual variation is characterized by a much stronger response (2-3 dB) during the warm growing season throughout the summer than that of the snow and ice covered winter. An even more rapid transition is observed for neighboring lichen woodlands. Tundra has a similar response during winter but differs during summer by about $1.5 \mathrm{~dB}$. Grasslands exhibit a much lower response year-round. Thus, the markedly different responses of these neighboring vegetation types should allow discrimination of Boreal forest and lichen woodland regions from tundra and grasslands during the summer. 

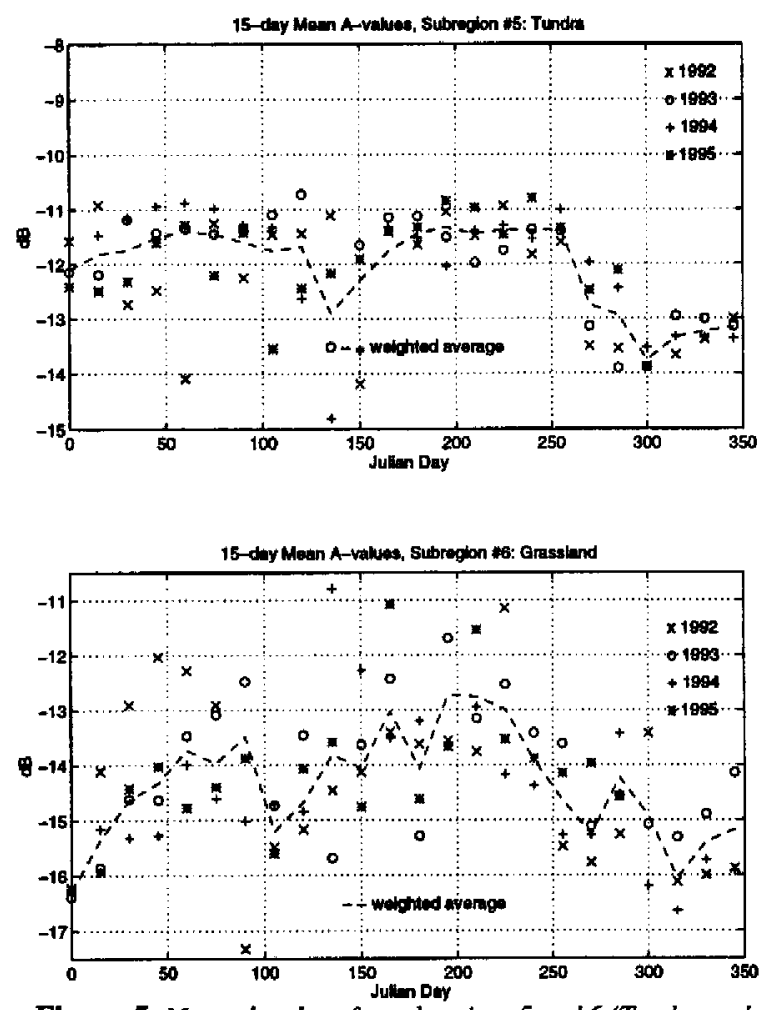

Figure 5: Mean A-values for subregions 5 and 6 (Tundra and Grassland) for 1992-1995

The use of spaceborne scatterometer measurements in combination with SIR image resolution enhancement is a valuable resource for the study of land regions such as boreal forests. With this technique, we have examined the boreal forest on a macroscopic level over several annual cycles. These successful results are substantial motivation for expanded research exploring the use of spaceborne scatterometer backscatter coefficient

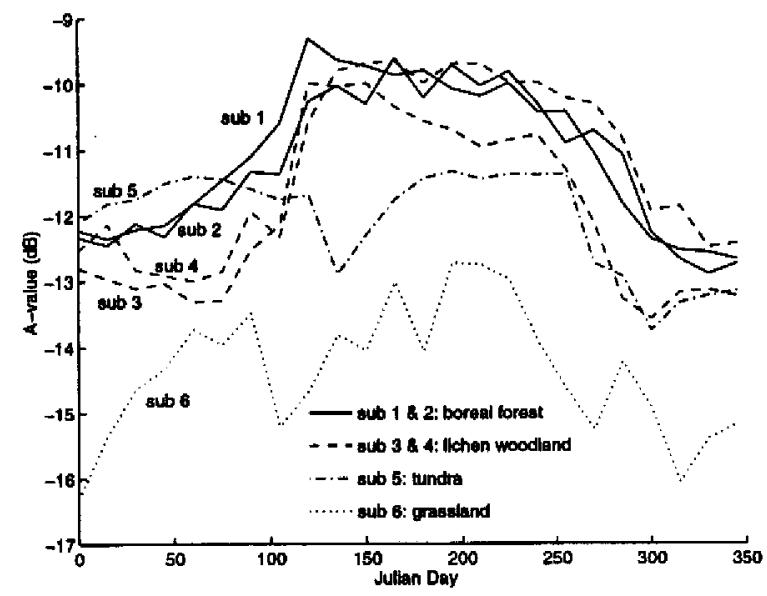

Figure 6: Weighted Mean A-values over all six subregions measurements for the study of boreal forest vegetation regions.

\section{REFERENCES}

[1] E. Mougin, A. Lopes, P. Frison, and C. Proisy, "Preliminary Analysis of ERS-1 Wind Scatterometer Data over Land Surfaces," International Journal of Remote Sensing, vol. 16, no. 2, pp. 391--398, 1995.

[2] R. Kennett and F. Li, "Seasat over Land Scatterometer Data, Part I: Global Overview of the Ku-band Backscatterer Coefficients," IEEE Transactions on Geoscience and Remote Sensing, vol. 27, pp. 592$605,1989$.

[3] R. Kennett and F. Li, "Seasat over Land Scatterometer Data, Part II: Selection of Extended Area Land-target Sites for the Calibration of Spaceborne Scatterometers,' IEEE Transactions on Geoscience and Remote Sensing, vol. 27, pp. 779--788, 1989.

[4] D. Long, P. Hardin, and P. Whiting, "Resolution Enhancement of Spaceborne Scatterometer Data," IEEE Transactions on Geoscience and Remote Sensing, vol. 31, pp. 700--715, May 1993.

[5] D. Long and P. J. Hardin, "Vegetation Stüdies of the Amazon Basin Using Enhanced Resolution Seasat Scatterometer Data," IEEE Transactions on Geoscience and Remote Sensing, vol. 32, pp. 449-460, March 1994.

[6] D. Long, D. Early, and M. Drinkwater, "Enhanced Resolution ERS-1 Scatterometer Imaging of Southern Hemisphere Polar Ice," IGARRS '94, vol. 1, pp. 156-158, 1994.

[7] H. Shugart, R. Leemans, and G. Bonan, eds., A Systems Analysis of the Global Boreal Forest. Cambridge, Great Britain: Cambridge University Press, 1992. 